\title{
Luciferin inspired oxygen sensing with alternant change of color and fluorescence
}

Yu-Mo Zhang ${ }^{1}$, Jingjing Zhang ${ }^{1}$, Sean Xiao-An Zhang ${ }^{1,2} *$

1. State Key Laboratory of Supramolecular Structure and Materials, College of Chemistry, Jilin

University, Changchun 130012, P.R. China.E-mail: seanzhang@jlu.edu.cn

2. Department of Chemistry and Pharmacy, Zhuhai College of Jilin University, Zhuhai 519041,

China.

ABSTRACT. Inspired by enol-degradation of luciferin, a new dual mode oxygen sensing with alternant change of color and fluorescence has been developed to estimate rapidly the oxygen concentration. Based on the screening of ten methyl ketone molecules with different functional groups, molecule M5 with obvious fluorescence change and high degradation speed is selected and studied in detail by UV-Vis and fluorescence spectroscopy. The degradative mechanism containing four-member ring intermediate has been proved by MS and DFT calculation. And the sensor strip prepared by molecule M5 exhibits high selective and perfect optical properties to detect the oxygen concentration without delicate instrument. This oxygen sensor will not only accelerate the development of oxygen sensor, but will also help to understand the mechanism of luciferin bio-degradation.

\section{Introduction:}

C 2016 . This manuscript version is made available under the Elsevier user license http://www.elsevier.com/open-access/userlicense/1.0/ 
As one of the essential components of atmosphere, oxygen plays a crucial role in living system, industry and environment[1,2]. Oxygen detecting and monitoring has been a hot research topic for analyzing of environmental pollution[3], understanding the mechanism of physiology[4,5,6], tracking of cancer states[7,8], and so on. In the past decades, many practical oxygen sensors have been developed and applied, such as polarographic electrochemistry[9,10], resonance techniques[11,12], colorimetry[13,14,15] and luminescence-based method[16,17]. Thereinto, colorimeter based on the color change of oxygen-sensing materials exhibits attractive advantages, such as simple materials, independent on the precise instrument. However, the low sensitivity and long responsive time of materials limit their application[18]. Luminescence-based method for oxygen sensing, which rely on the change in emission, possesses advantages of the fast responsive speed and the high sensitivity [19,20,21,22]. But, some intrinsic problems, such as needing the precise instrument and complicated mechanism, hinder their practical application[23]. Thus, the two kinds of oxygen sensing materials may complement each other. And multipurpose oxygen sensing with colorimetry and luminescence-based method has been hoped to be developed.

In our group, we focus attention on methyl ketone molecules[24,25] that exhibit alternative change of color and fluorescence in the present of oxygen and base[26] inspired by the enoldegradation of luciferin[27,28,29], as shown in Scheme 1. In the design, luciferase is replaced by chemical base to capture $\alpha-\mathrm{H}$, and then enolate anion of methyl ketone molecules, similar with enolate anion of luciferin-AMP, reactions with oxygen spontaneously. However, too long response time of color change ranging from a few hours to several days can not exhibit merit of dual-mode oxygen sensing with color and fluorescence change[26]. In order to expand application of oxygen sensing, we should develop a oxygen sensing with fast response time. In 
this paper, oxygen sensing M5 with obvious fluorescence change and high response rate of color chenge has been developed. And degradative mechanism containing four-member ring intermediate has been demonstrated successfully, which can help to understand the mechanism of luciferin bio-degradation.

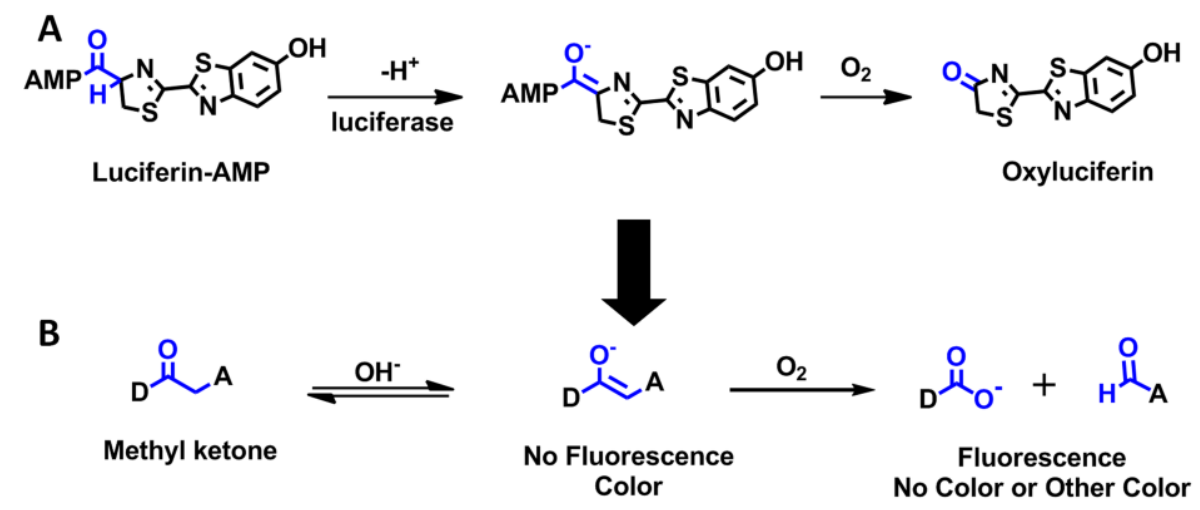

Scheme 1. Schematic diagram of design for oxygen sensing with methyl ketone group, inspired by enol-degradation of firefly.

\section{Results:}

To reduce the response time of methyl-ketone-based oxygen sensing, one of important methods is to enhance the reactivity of $\alpha-\mathrm{C}$ with oxygen by modified the electron-donor substituent in A group. However, this method increases the difficulty of $\alpha-\mathrm{H}$ extraction, and then decrease the concentration of enolate anion of methyl ketone molecule in enol-ketone isomerization reaction. Thus, simply increasing or decreasing the ability of electron donor in A group might not improve the response time of oxygen sensing. For proof-of principle, a series of oxygen sensing molecules with different donor groups, acceptor groups, and aromatic rings, were designed and synthesized/prepared for rapid screening of the suitable oxygen sensing. All molecules were synthesized/prepared based on our previous work, and the synthetic process of M5 and M10 were shown in Supplementary Information. As shown in Figure 1, molecule M9 
with nitro group exhibits obvious color change, but has poor response time about 2 days. Molecule M2 shows better response time, but exhibits obscure color change from light yellow to colorless. Fortunately, molecule M5 with 5-nitronaphthalene group exhibits high response speed (7 min) and significant color change from yellow green to yellow. Therefore, the results of the fast test show that properties (response time and contrast) of oxygen sensing based on methyl ketone molecule is dependent on the substituent of A group. And the following research of oxygen sensing is based on M5.
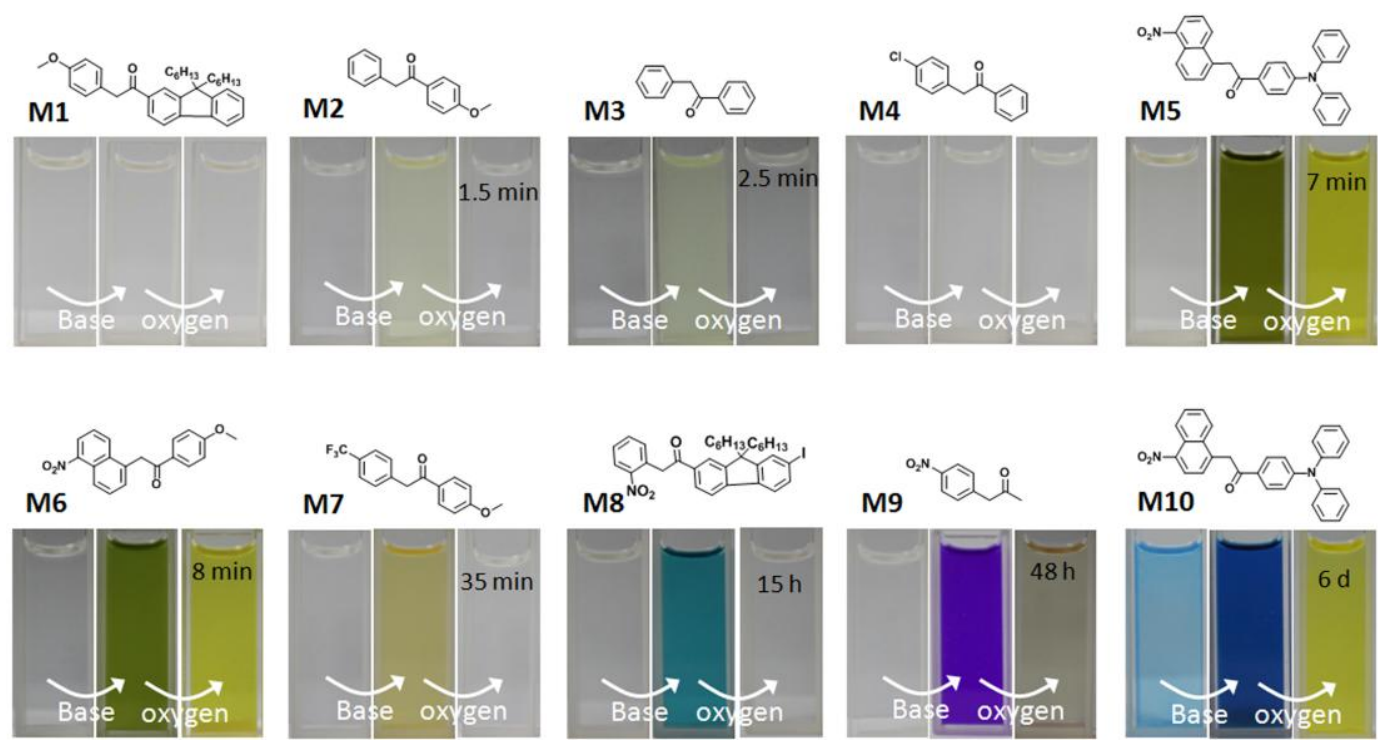

Figure 1. The color change of ten methyl ketone molecules stimulated by base (t-BuOK, 100 eq) firstly under $\mathrm{N}_{2}$ (the second picture), then exposed to oxygen (the third picture) in DMF. Note: the responsive time of the color change provided in the third picture; M1 and M4: no obvious color change.

The ketone-enol isomerization of M5 as the first step for the oxygen sensing is explored firstly. As shown in Figure $2 \mathrm{a}$ and $\mathrm{b}$, the colorless $(352 \mathrm{~nm})$ and transparent of M5 solution was instantly changed to yellow-green color $\left(667 \mathrm{~nm}\right.$ and $443 \mathrm{~nm}$ ) stimulated by 30 eq base in $\mathrm{N}_{2}$. And the ketone-enol isomerization can be reverted by acid reversibly, along with the reversible 
color change from yellow-green color to colorless. Thus, M5 similar to other methyl ketone molecules can be isomerizated to enolate anion by base. In addition, M5 emitted a weak fluorescence at $440 \mathrm{~nm}$ came from triphenylamine group, which can be detected by fluorescence spectrometer as shown in the black curve of Figure $2 \mathrm{~b}$, but can not be observed by naked eye. The enolate of M5 obtained by the addition of base has no fluorescence as shown in red curve of Figure 2b. Thus, the process of ketone-enol isomerization has no obvious change of fluorescence.
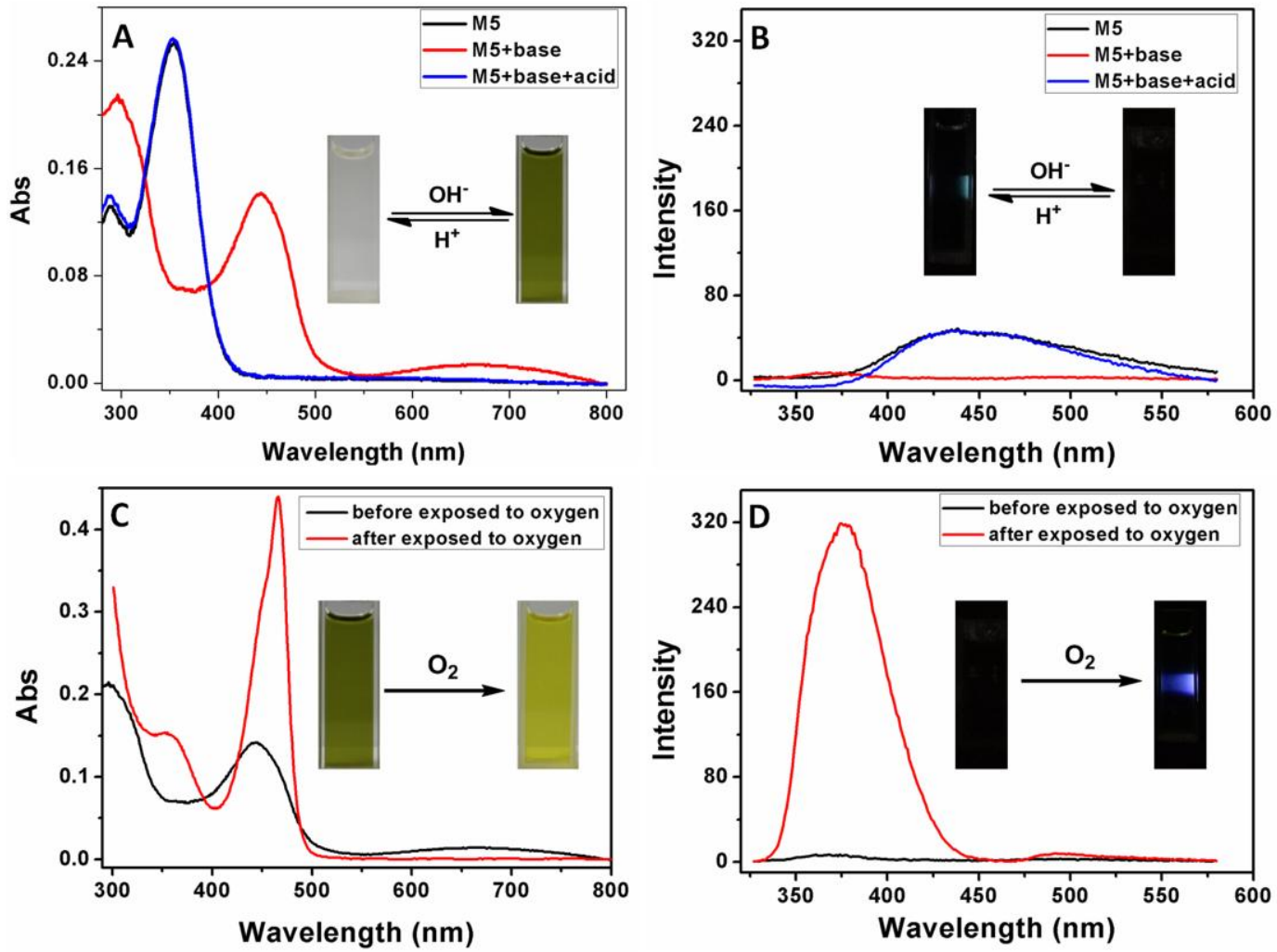

Figure 2. Absorption (a) and fluorescence (b) spectra of M5 (1.0 × 10 ${ }^{-5} \mathrm{M}$, black curve) in DMF, treated with t-BuOK (30 eq, red curve), and then neutralized with $\mathrm{CF}_{3} \mathrm{COOH}$ (30 eq, blue curve). (c) Absorption spectra (c) and fluorescence (d) spectra of M5 (1.0 $\left.\times 10^{-5} \mathrm{M}\right)$ treated with 30 eq t-BuOK in DMF, before (black curve) and after (red curve) exposed to oxygen. 
Then, enol-degradation of M5 is studied by absorption and fluorescence spectra. From Figure $2 \mathrm{c}$ and $\mathrm{d}$, a new peak at $466 \mathrm{~nm}$ was appeared, along with the decrease of the intensity of yellowgreen color at $443 \mathrm{~nm}$ and $667 \mathrm{~nm}$ after the M5-enolate solution was exposed to oxygen. And a blue fluorescence was appeared at $375 \mathrm{~nm}$ which was proposed as the product of enoldegradation. Thus, the M5-enolate was sensitive to oxygen and can be used as oxygen sensing, as our expectations. To further research of the enol-degradation mechanism, the solution of M5enolate was detected by MS after exposed to oxygen. As shown in Figure S1, a major peak with a molecular mass of 218.0 (retention time at $3.0 \mathrm{~min}$ ) in HPLC-MS spectrum is identical with the theoretical molecular weight of 5-nitro-1-naphthoic acid (M+H: 218.0), and a another major peak with 290.1 (retention time at $3.2 \mathrm{~min}$ ) is same as the theoretical molecular weight of 4(diphenylamino)benzoic acid (M+H: 290.1). Thus, 5-nitro-1-naphthoic acid and 4(diphenylamino)benzoic acid is the product of the enol-degradation.

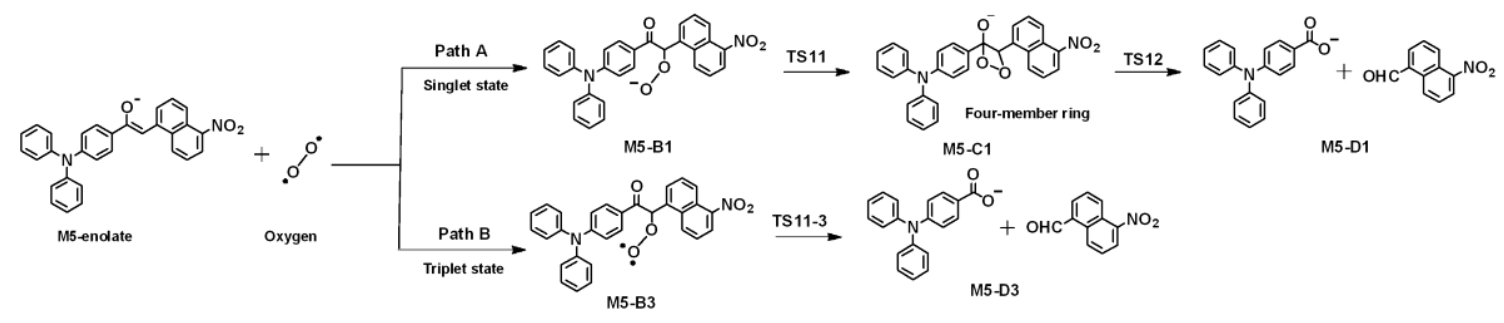

Figure 4. The postulated enol-degradation mechanism of M5.

Due to oxygen is triplet state and the product is single state, the bio-inspired degradative reaction is a spin forbidden process. Thus, two alternative mechanisms were proposed in Figure 4: 1) the singlet state $\mathrm{C}-\mathrm{O}$ bond was formed via a single electron-transfer mechanism[31] containing a diradical intermediate, denoted as Path A (singlet state); 2) the degradative reaction is triplet state process, denoted as Path B. In order to further understand enol-degradation, DFT method is used to analyze the mechanism of enol-degradation reaction. All structures of intermediates and transition states of Path A and Path B were optimized by M06/6-31+G(d)[30] 
as shown in Figure 5 and 6. One transition state TS11-3 containing the four-member ring is found in path B with triplet state in Figure 5. The dihedral angle of $\mathrm{C} 1-\mathrm{C} 2-\mathrm{O} 2-\mathrm{O} 3$ is $-23.3^{\circ}$, and C1-O3 length is $1.86 \AA$ in TS11-3. Due to the four-member ring M5-C1 as a intermediate, not transition state, Path A is different from path B obviously, and the activation energy of path A $(6.59 \mathrm{kcal} / \mathrm{mol})$ with singlet state is lower than path B $(26.90 \mathrm{kcal} / \mathrm{mol})$ with triplet state. In the path A, two transition states and one intermediate are found as shown in Figure 6. The dihedral angle of $\mathrm{C} 1-\mathrm{C} 2-\mathrm{O} 2-\mathrm{O} 3$ in the transition states TS11 is $-74.1^{\circ}$, and, the length of $\mathrm{O} 2-\mathrm{O} 3$ and $\mathrm{C} 2$ O2 is $1.45 \AA$ and $1.39 \AA$, respectively. Thus, the trend of transition states TS11 is to form the four-member ring. More importantly, the intermediate M5-C1 containing four-ring member exibits a small dihedral angle of C1-C2-O2-O3 $\left(3.87^{\circ}\right)$. After overcoming $7.53 \mathrm{kcal} / \mathrm{mol}$, the $\mathrm{C} 1$ $\mathrm{C} 2$ of the four-member ring begins to split by analyzing the structure feature of transition state TS12. Thus, the increase of C1-C2 length is a major driving force for the cleavage of fourmember ring, rather than $\mathrm{O} 1-\mathrm{O} 2$. With the length of $\mathrm{C} 1-\mathrm{C} 2$ increasing, the bond energy of $\mathrm{C} 2-\mathrm{A}$, $\mathrm{C} 2-\mathrm{O} 1$ and $\mathrm{C} 1-\mathrm{O} 3$ increases, and $\mathrm{C} 2-\mathrm{O} 2$ bond exhibits double bond feature by analyzing the bond length. Thus, the whole reaction is exothermic and involves two steps containing the formation of four-member ring and the cleavage of four-member ring. And the activation energy of degradation reaction is $7.53 \mathrm{kcal} / \mathrm{mol}$, which indicates that this reaction in Path A happen spontaneously at room temperature. 


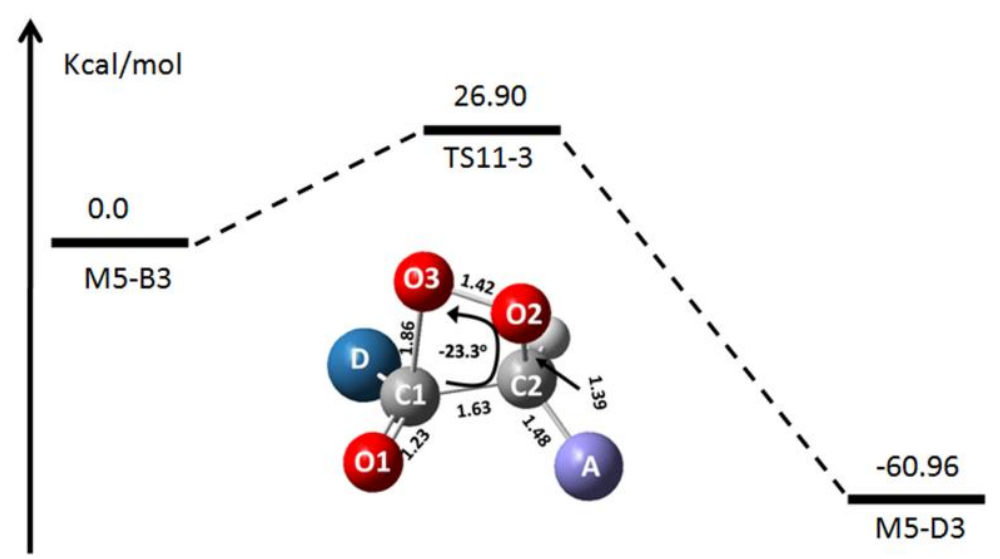

Figure 5. Computed energy profiles for enol-degradation of M5 in Path B with triplet state. Geometric structures of transition states TS11-3 (distance in $\AA$ ) involved in the energy profiles. 5-nitronaphthalene and triphenylamine group were simplified as A and D for clarity.

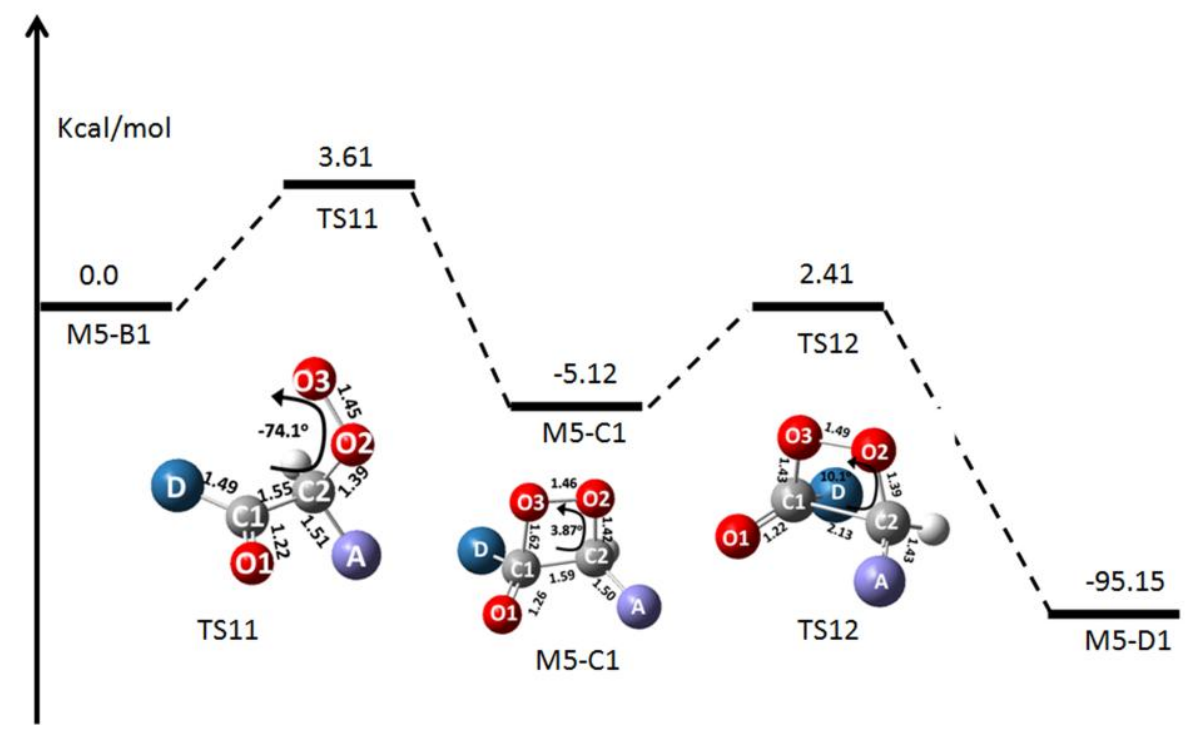

Figure 6. Computed energy profiles for enol-degradation of M5 in Path A with singlet state. Geometric structures of transition states TS11, intermediate M5-C1, and transition states TS12 (distance in $\AA$ ) involved in the energy profiles. 5-nitronaphthalene and triphenylamine group were simplified as A and D for clarity. 
All the results prompts us to propose a possible mechanism to explain the entire reaction. As shown in Figure 4, M5-enolate is generated firstly; then oxygen is added to M5-enolate to form a unstable intermediate with four-member ring which subsequently decomposes into thermodynamically more favorable 5-nitro-1-naphthaldehyde and 4-(diphenylamino)benzoic acid. Finally, the 5-nitro-1-naphthaldehyde is oxidized to 5-nitro-1-naphthoic acid. From the theoretical calculation and experimental results, the degradation of M5-enolate is same as the degradation of dioxetanone for bioluminescence in firefly[13], except the decomposition of fourmember ring in the last step. Thus, the two enol-degradation reactions have similar mechanism, but have different products, and the enol-degradation of M5-enolate can not produce light. Based on this proposed mechanism, we will try to design a new methyl ketone molecule with chemiluminescence properties in our further work. Based on the proposed mechanism, the degradation rate is dependent on the reaction rate of the electrophilic reaction of enolate form with oxygen. In other word, the response time of methyl-ketone-based oxygen sensing is opposite to the charge of $\alpha-\mathrm{C}$ calculated by M06/6-31+G (d) and NBO method as shown in Table S1. Thus, enolate form of M5, with a charge of -0.456 for $\alpha-C$, has a faster response rate than that of similar structure M10, with a charge of -0.426 for $\alpha-C$. 

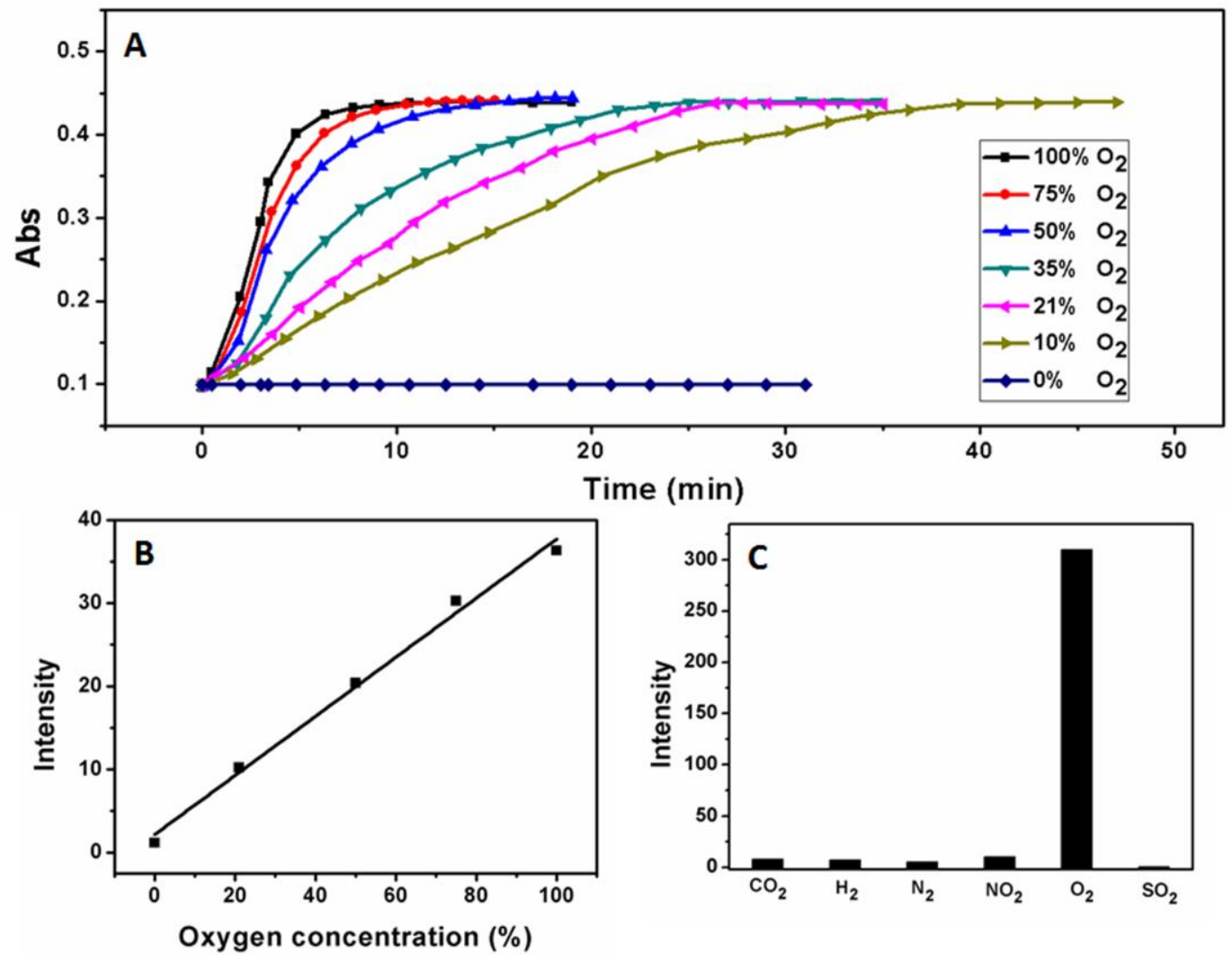

Figure 7. (a) Absorbance (at $466 \mathrm{~nm})$ changes of M5 $\left(1.0 \times 10^{-5} \mathrm{M}, \mathrm{DMF}, 30 \mathrm{eq} \mathrm{t}-\mathrm{BuOK}\right)$ in the present of different concentration of oxygen $(0 \%, 10 \%, 21 \%, 35 \%, 50 \%, 75 \% 100 \%)$. (b) Fluorescence intensity changes $(375 \mathrm{~nm})$ of M5 $\left(1.0 \times 10^{-3} \mathrm{M}\right.$, DMF, 30 eq t-BuOK) with the concentration of oxygen recorded at $1 \mathrm{~min}$. (c) Fluorescent response $(375 \mathrm{~nm})$ of M5 $\left(1.0 \times 10^{-3}\right.$ $\mathrm{M}, 30$ eq $\mathrm{t}-\mathrm{BuOK})$ to various common environmental interferents $\left(\mathrm{CO}_{2}, \mathrm{H}_{2}, \mathrm{~N}_{2}, \mathrm{NO}_{2}, \mathrm{O}_{2}, \mathrm{SO}_{2}\right)$ in DMF solution.

In order to apply the bio-inspired reaction to qualitative and quantitative analysis of oxygen, the change of the emission and absorbance of M5-enolate vs. oxygen concentration and time are monitored closely. As shown in Figure 7A, with oxygen concentration increasing, the rate of enol-degradation and the intensity of absorbance at $466 \mathrm{~nm}$ as the characteristic peak of the production of enol-degradation also increase, and the reaction time of enol-degradation 
decreases, such as $7 \mathrm{~min}$ for $100 \%$ oxygen, $16 \mathrm{~min}$ for $35 \%$ oxygen, and $28 \mathrm{~min}$ for $10 \%$ oxygen. Thus, the time of the color change can be used to semi-quantitative estimation of oxygen concentration. At the beginning of enol-degradation, the concentration of M5-enolate is excess. Thereinto, the rate of enol-degradation is dependent on the concentration of oxygen concentration. The intensity of the absorbance at $466 \mathrm{~nm}$ increases linearly and proportionally with oxygen concentration at the start of enol-degradation, as shown in Figure 7A. And, the fluorescence intensities are linearly proportional to the concentration of oxygen in the range of $0 \%-100 \%$ at the beginning of enol-degradation (1 min, Figure 7B). The linear relationship between the intensity of the fluorescence and oxygen concentration reveals its good potential for accurate oxygen sensing. When the intensity of the absorbance at $466 \mathrm{~nm}$ is greater than 0.3 , which indicates that the half of the enol-degradation has been occurred, the rate of enoldegradation is dependent on the concentration of M5-enolate. Thus, the rate of enol-degradation has been become complex.

The selectivity of the sensor toward different common environmental interferents including $\mathrm{CO}_{2}, \mathrm{H}_{2}, \mathrm{NO}_{2}, \mathrm{SO}_{2}, \mathrm{NO}$, and $\mathrm{Ar}$ was also studied. As shown in Figure $7 \mathrm{C}$, the fluorescence of M5 exhibits obvious enhancement only in the presence of oxygen, and no obvious change in fluorescence of $\mathrm{M} 5$ under $\mathrm{CO}_{2}, \mathrm{H}_{2}, \mathrm{NO}_{2}, \mathrm{SO}_{2}, \mathrm{NO}$, and $\mathrm{Ar}$ atmospheres. It indicated that the oxygen sensor has a highly selective toward oxygen. 


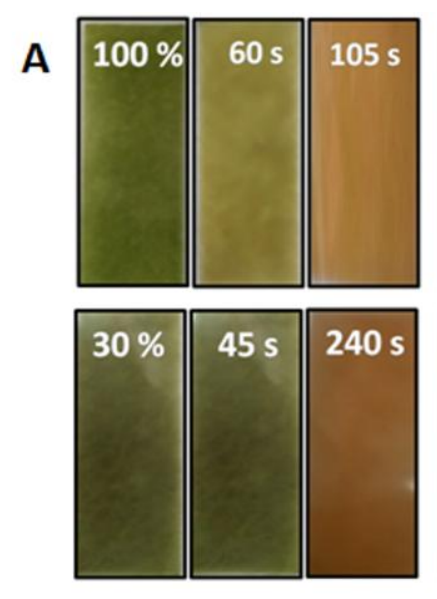

B

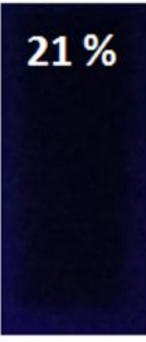

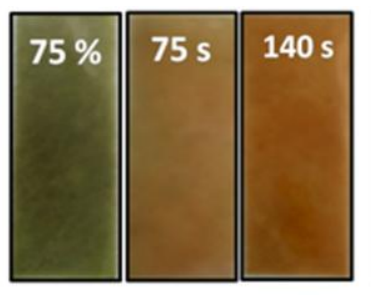
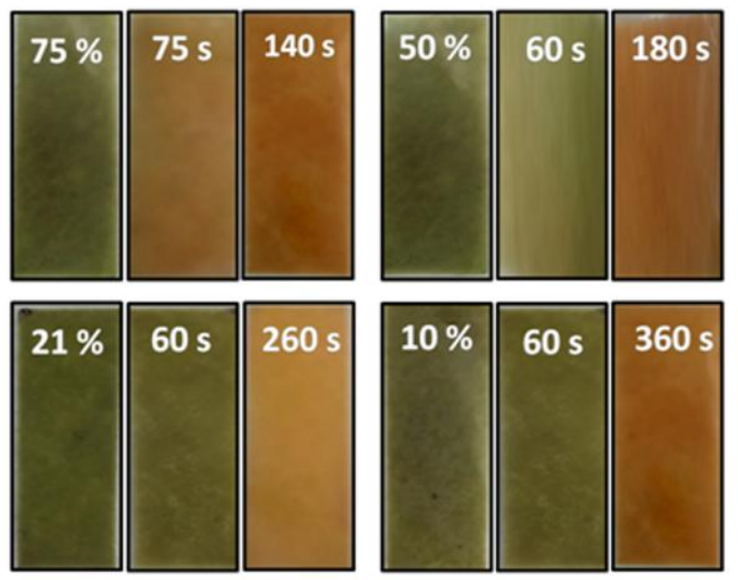

C
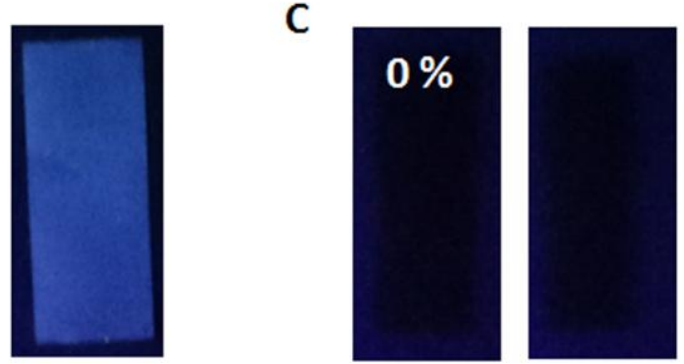

Figure 8. (A) The color change of paper based sensor strip with different oxygen concetration; (b) photographs of test strips before and after exposed in (B) $21 \%$ oxygen and (C) $0 \%$ oxygen (in glove box) under $365 \mathrm{~nm}$ UV light.

To make this sensor more convenient for practical application, M5-enolate is integrated into filter paper (see ESI). As shown in Figure 8, the dark green strip can be maintained, and the fluorescence can not be observed if the strip is exposed in nitrogen environment. However, the obvious blue fluorescence can be detected instantly, and the green color is converted to yellow color gradually, when the sensor is exposed in oxygen environment. And, the concentration of oxygen is proportional to the logarithm of the degradation time of the sensor strip (Figure S2). The preliminary experiment results indicate that the M5-enolate strip sensor can be used in the rapid detection for oxygen by fluorescence change, and the semi-quantitative detection for oxygen concentration by the color change. Thus, this dual-mode sensor with alternant change of color and fluorescence don't need sophisticated instruments, and is well suited for monitoring 
oxygen concentration (Figure S3) in an outdoor environment, such as valley, cellar, and a strange space. The operation method of the sensor strip: the fluorescence change can be observed by laser pointer firstly to determine if the round contains oxygen when the strip is exposed in unknown environment; then the color change time can be recorded by the naked eye and stopwatch to estimate the oxygen concentration. For example 1, the strip exhibits the blue fluorescence, and the degradation time is in the range of $260 \mathrm{~s}$ to $240 \mathrm{~s}$ which indicates that the oxygen concentration is about $18 \%-30 \%$. Thus, the detected environment may be the suitable living environment for human. For example 2, we can confirm that there is the little or no oxygen round, if no obvious blue fluorescence can be detected when the sensor strip is exposed in unknown environment. For example 3, the oxygen concentration is more than $50 \%$, if the degradation time is less than $180 \mathrm{~s}$. That is to say, the detected environment is deadly to human due to oxygen-rich. In a word, the dual mode oxygen sensing inspired by luciferin can be applied to estimate oxygen concentration. It is still important to note that this method, similar to other luciferin/luciferase based sensors[32], is irreversible and one time. And we will try to optimize our method to develop multi-used sensor in our further work.

\section{Conclusions}

In summary, M5 with high degradation rate of color and obvious fluorescence change is selected as oxygen sensor to exhibit the advantages of dual mode, based on the screening of ten methyl ketone molecules with different groups. The basochromic property, with the color change from colorless to yellow-green, and the enol-degradation property, with the color change from dark green to yellow and the "turn-on" blue fluorescence, are studied by UV-Vis and fluorescence spectroscopy. The degradative path and mechanism of M5 was studied by UV-Vis spectroscopy, fluorescence spectroscopy, MS and DFT calculation in detail. And the four- 
member ring intermediate is found by DFT calculation. More importantly, the sensor strip with high selective and perfect optical properties is prepared to detect the oxygen concentration without delicate instrument. This oxygen sensor will not only accelerate the development of oxygen sensor, but will also help to understand the bio-degradation mechanism of luciferin.

\section{Acknowledgements:}

This study was supported by the National Science Foundation of China (Grant No. 51373068, 21602075) and the program of Chang Jiang Scholars and Innovative Research Team in the University (IRT101713018) for financial support.

\section{Notes and references:}

[1] Roussakis, E.; Li Z.; Nichols, A. J.; Evans, C. L. Oxygen-Sensing Methods in Biomedicine from the Macroscale to the Microscale. Angew. Chem. Int. Ed. 2015, 54, 8340-8362.

[2] Morris, R. L.; Schmidt, T. M. Shallow Breathing: Bacterial Life at Low $\mathrm{O}_{2}$. Nat. Rev. Microbiol. 2013, 11, 205-212.

[3] Amao, Y. Probes and Polymers for Optical Sensing of Oxygen. Microchim. Acta 2003, 143, 1-12.

[4] Yu, J.; Cui, W.; Zhao D.; Mason R. P.; Mason in Fluorine and Health (Ed.: A. Tressaud), Elsevier, Amsterdam, 2008, 197-276.

[5] Lilly L. S.; School, H. M. Pathophysiology of Heart Disease: A Collaborative Project of Medical Students and Faculty, Wolters Kluwer/Lippincott Williams\&Wilkins, 2011. 
[6] Nelson, N. Photosystems and Global Effects of Oxygenic Photosynthesis. Biochim. Biophys. Acta, Bioenerg. 2011, 1807, 856-863.

[7] Song, X.; Liu, X.; Chi, W.; Liu, Y.; Wei, L.; Wang. X.; Yu, J. Hypoxia-induced Resistance to Cisplatin and Doxorubicin in Non-small Cell Lung Cancer is Inhibited by Dilencing of HIF$1 \alpha$ Gene. Cancer Chemother. Pharmacol. 2006, 58, 776-784.

[8] Xu, R.-h.; Pelicano, H.; Zhou, Y.; Carew, S. J.; Feng, L. Bhalla, K. N. Keating, M. J.; Huang P. Inhibition of Glycolysis in Cancer Cells: A Novel Strategy to Overcome Drug Resistance Associated with Mitochondrial Respiratory Defect and Hypoxia. Cancer Res. 2005, $65,613-621$.

[9] Chen, X.; Tian, X.; Shin, I.; Yoon, J. Fluorescent and Luminescent Probes for Detection of Reactive Oxygen and Nitrogen Species. Chem. Soc. Rev. 2011, 40, 4783-4804.

[10] Buerk, D. G. Measuring Tissue $\mathrm{pO}_{2}$ with Microelectrodes. Methods Enzymol. 2004, 381, $665-690$.

[11] Christen, T.; Bolar, D. S.; Zaharchuk, G. Imaging Brain Oxygenation with MRI using Blood Oxygenation Approaches: Methods, Validation, and Clinical Applications. Am. J. Neuroradiol. 2013, 34, 1113-1123.

[12] Gallez, B.; Baudelet, C.; Jordan, B. F. Assessment of Tumor Oxygenation by Electron Paramagnetic Resonance: Principles and Applications. NMR Biomed. 2004, 17, 240 -262.

[13] Wang, X.; Chen, H.; Zhao, Y.; Chen, X.; Wang, X. Optical Oxygen Sensors Move Towards Colorimetric Determination. Trends in Anal. Chem. 2010, 29, 319-338. 
[14] Faber, D. J.; Mik, E. G.; Aalders, M. C.; van Leeuwen, T. G. Toward Assessment of Blood Oxygen Saturation by Spectroscopic Optical Coherence Tomography. Opt. Lett. 2005, 30, $1015-1017$.

[15] Chen, X.; Wang, F.; Hyun, J. Y.; Wei, T.; Qiang, J.; Ren, X.; Shin, I.; Yoon, J. Recent Progress in the Development of Fluorescent, Luminescent and Colorimetric Probes for Detection of Reactive Oxygen and Nitrogen Species. Chem. Soc. Rev., 2016, 45, 2976-3016.

[16] Wang, X.; Wolfbeis, O. S. Optical Methods for Sensing and Imaging Oxygen: Materials, Spectroscopies and Applications. Chem. Soc. Rev. 2014, 43, 3666 -3761.

[17] Clark, L. C.; Wolf, R.; Granger. D.; Taylor, Z. Continuous Recording of Blood Oxygen Tensions by Polarography. J. Appl. Physiol. 1953, 6, 189-193. [18] Wang, L. V.; Hu, S. Photoacoustic Tomography: in vivo Imaging from Organelles to Organs. Science 2012, 335, $1458-1462$.

[19] Ji, S.; Wu, W.; Wu, W.; Song, P.; Han, K.; Wang, Z.; Liu, S.; Guo, H.; Zhao J. Tuning the Luminescence Lifetimes of Ruthenium(II) Polypyridine Complexes and its Application in Luminescent Oxygen Sensing. J. Mater. Chem., 2010, 20, 1953-1963.

[20] Wu, W.; Wu, W.; Ji, S.; Guo, H. Zhao, J. Accessing the Long-lived Emissive ${ }^{3}$ IL Triplet Excited States of Coumarin Fluorophores by Direct Cyclometallation and its Application for Oxygen Sensing and Upconversion. Dalton Trans., 2011, 40, 5953-5963.

[21] Zhao, J.; Ji, S.; Wu, W.; Wu, W.; Guo, H.; Jifu Sun, J.; Sun, H.; Liu, Y.; Li, Q.; Huang, L. Transition metal complexes with strong absorption of visible light and long-lived triplet excited states: from molecular design to applications. $R S C A d v ., \mathbf{2 0 1 2}, 2,1712-1728$. 
[22] Feng, Y.; Cheng, J.; Zhou, L.; Zhou, X.; Xiang, H. Ratiometric optical oxygen sensing: a review in respect of material design. Analyst, 2012, 137, 4885-4901.

[23] Papkovsky, D. B.; Dmitriev, R. I. Biological Detection by Optical Oxygen Sensing. Chem. Soc. Rev. 2013, 42, 8700-8732.[24] Zhang, Y.-M.; Li, M.; Li, W.; Huang, Z.; Zhu, S.; Yang, B.; Wang, X. -C.; Zhang, S. X. -A. A New Class of "Electro-acid/base"-induced Reversible Methyl Ketone Colour Switches. J. Mater. Chem. C, 2013, 1, 5309-5314.

[25] Zhang, Y.M.; Xie, F.; Li, W.; Wang, Y.; Zhang, W.; Wang, X.; Li M.; Zhang, S. X. -A. A Methyl Ketone Bridged Molecule as a Multi-stimuli-responsive Color Switch for Electrochromic Devices. J. Mater. Chem. C, 2016, 4, 4662 - 4667.

[26] Zhang, Y.M.; Wang, X.; Li, W.; Zhang, W.; Li M.; Zhang, S. X. -A. Bio-inspired Enoldegradation for Multipurpose Oxygen Sensing. Chem. Commun. 2014, 50, 13477-13480.

[27] Li, J.; Chen, L.; Du, L.; Li, M. Cage the Firefly Luciferin!-a Strategy for Developing Bioluminescent Probes. Chem. Soc. Rev. 2013, 42, 662-676.

[28] Navizet, I.; Liu, Y.-J.; Ferré, N.; Xiao, H.-Y.; Fang, W.-H.; Lindh, R. Color-tuning Mechanism of Firefly Investigated by Multi-configurational Perturbation Method. J. Am Chem. Soc. 2010, 132, 706-712.

[29] Nakatsu, T.; Ichiyama, S.; Hiratake, J.; Saldanha, A.; Kobashi, N. Sakata, K.; Kato, H. Structural Basis for the Spectral Difference in Luciferase Bioluminescence. Nature 2006, 440, $372-376$.

[30] Frisch, M. J.; Trucks, G. W.; Schlegel, H. B.; Scuseria, G. E.; Robb, M. A.; Cheeseman, J. R.; Scalmani, G.; Barone, V.; Mennucci, B.; Petersson, G. A.; Nakatsuji, H.; Caricato, M.; Li, X.; 
Hratchian, H. P.; Izmaylov, A. F.; Bloino, J.; Zheng, G.; Sonnenberg, J. L.; Hada, M.; Ehara, M.; Toyota, K.; Fukuda, R.; Hasegawa, J.; Ishida, M.; Nakajima, T.; Honda, Y.; Kitao, O.; Nakai, H.; Vreven, T.; Montgomery, J. A.; Peralta, J. E.; Ogliaro, F.; Bearpark, M.; Heyd, J. J.; Brothers, E.; Kudin, K. N.; Staroverov, V. N.; Kobayashi, R.; Normand, J.; Raghavachari, K.; Rendell, A.; Burant, J. C.; Iyengar, S. S.; Tomasi, J.; Cossi, M.; Rega, N.; Millam, J. M.; Klene, M.; Knox, J. E.; Cross, J. B.; Bakken, V.; Adamo, C.; Jaramillo, J.; Gomperts, R.; Stratmann, R. E.; Yazyev, O.; Austin, A. J.; Cammi, R.; Pomelli, C.; Ochterski, J. W.; Martin, R. L.; Morokuma, K.; Zakrzewski, V. G.; Voth, G. A.; Salvador, P.; Dannenberg, J. J.; Dapprich, S.; Daniels, A. D.; Farkas, O.; Foresman, J. B.; Ortiz, J. V.; Cioslowski, J.; Fox, D. J. Gaussian 09, Gaussian, Inc., Wallingford, CT 2009.

[31] Branchini, B. R.; Behney, C. E.; Southworth, T. L.; Fontaine, D. M.; Gulick, A. M.; Vinyard, D. J.; Brudvig, G. W. Experimental Support for a Single Electron-Transfer Oxidation Mechanism in Firefly Bioluminescence. J. Am. Chem. Soc. 2015, 137, 7592-7595.

[32] Van de Bittner, G. C.; Bertozzi, C. R.; Chang, C. J. J. Am. Chem. Soc. 2013, 135, 17831795. 


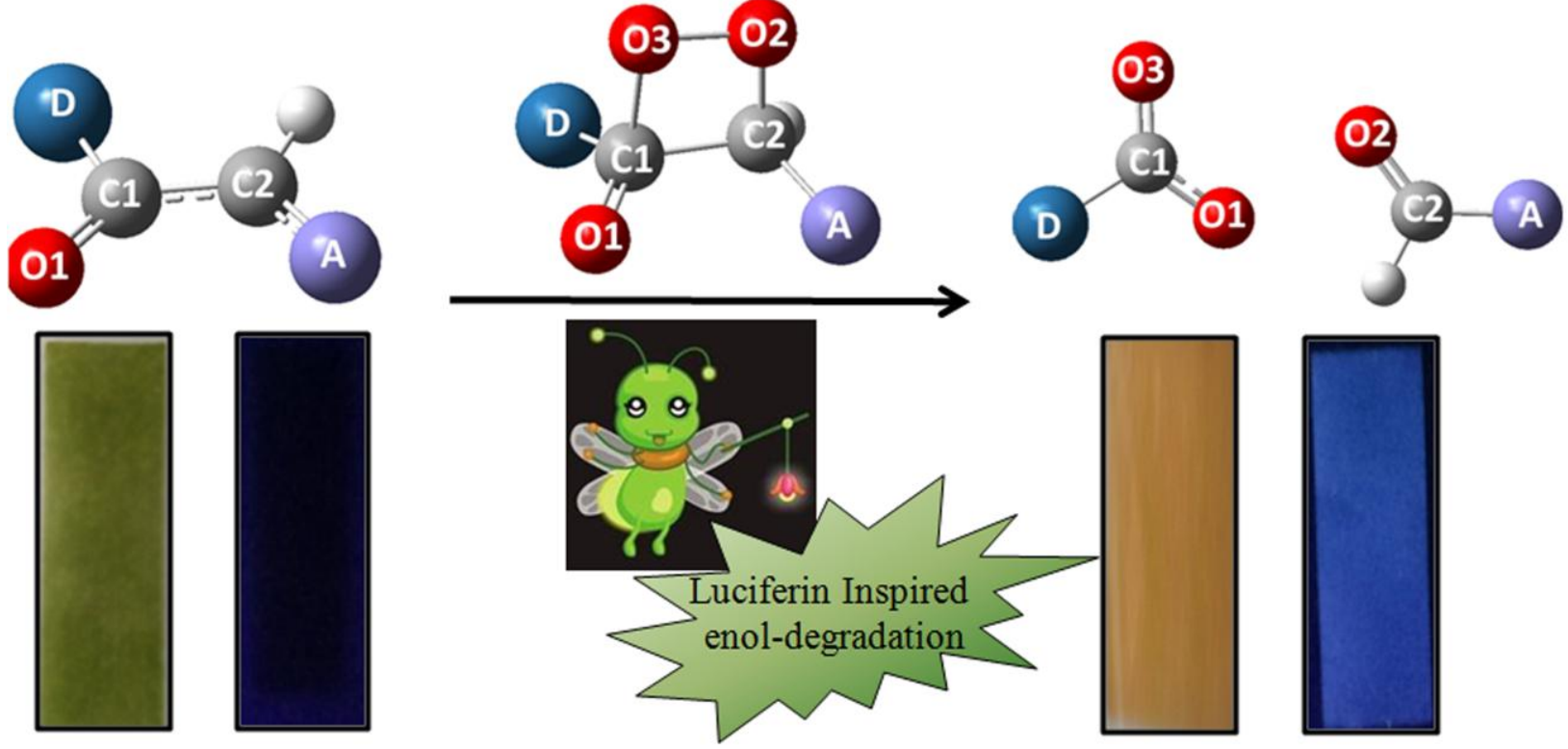

